\title{
Isolated spinal artery aneurysm: a rare culprit of subarachnoid haemorrhage
}

\author{
Tony HT Sung *, Warren KW Leung, Bill MH Lai, Jennifer LS Khoo
}

\begin{abstract}
A B S T R A C T
Isolated spinal artery aneurysm is a rare lesion which could be accountable for spontaneous spinal subarachnoid haemorrhage. We describe the case of a 74-year-old man presenting with sudden onset of chest pain radiating to the neck and back, with subsequent headache and confusion. Initial computed tomography aortogram revealed incidental finding of subtle acute spinal subarachnoid haemorrhage. A set of computed tomography scans of the brain showed further acute intracranial subarachnoid haemorrhage with posterior predominance, small amount of intraventricular haemorrhage, and absence of intracranial vascular lesions. Subsequent magnetic resonance imaging demonstrated a thrombosed intradural spinal aneurysm with surrounding sentinel clot, which was
\end{abstract}

trapped and excised during surgical exploration. High level of clinical alertness is required in order not to miss this rare but detrimental entity. Its relevant aetiopathological features and implications for clinical management are discussed.

\begin{tabular}{l} 
Hong Kong Med J 2015;21:179-82 \\
\hline DOI: 10.12809/hkmj144230 \\
THT Sung *, MB, ChB, FRCR \\
WKW Leung, FHKCR, FHKAM (Radiology) \\
BMH Lai, MB, BS, FRCR \\
JLS Khoo, FHKCR, FHKAM (Radiology) \\
Department of Radiology, Pamela Youde Nethersole Eastern Hospital, \\
Chai Wan, Hong Kong \\
* Corresponding author: sht557@ha.org.hk; tttony100@gmail.com
\end{tabular}

\section{Introduction}

Aneurysmal subarachnoid haemorrhage (SAH) is an uncommon but fatal clinical event. The reported incidence in a recent international population-based epidemiological study ranged between 2 and 16 per 100000 population, ${ }^{1}$ and the mortality rate ranged from $8 \%$ to $67 \% .^{2}$ Among all SAH cases, less than $1 \%$ are considered to originate from the spine. ${ }^{3} \mathrm{We}$ present a case of isolated spinal artery aneurysm as a rare culprit of spinal and intracranial SAH to illustrate the diagnostic challenge, its relevant aetiopathological features, and implications for clinical management.

\section{Case report}

A 74-year-old Chinese man with a history of hypertension and ischaemic heart disease presented to the Accident and Emergency Department in February 2013 for sudden onset of chest pain radiating to the neck and back. Clinical examination and electrocardiogram on admission showed no evidence of myocardial infarction. Initial working diagnosis of acute aortic dissection was also excluded with urgent computed tomography (CT) aortogram. On retrospective analysis, subtle but definite hyperdensities within the thecal sac at upper thoracic levels were noted, suggestive of acute spinal SAH (Fig 1).
The patient developed gradual progressive headache and confusion requiring intubation on the fourth day of admission. Plain CT of the brain at that time revealed further diffuse acute $\mathrm{SAH}$ with predominance over the posterior aspect, as well as a small amount of acute intraventricular haemorrhage. No skull vault fracture was observed. Concurrent CT cerebral arteriogram and venogram did not demonstrate any aneurysms or venous sinus thrombosis. Subsequent digital subtraction angiogram (DSA) of cerebral arteries performed on the next day was unremarkable.

In view of posterior predominance of the intracranial SAH with negative cerebral angiograms, an urgent magnetic resonance imaging (MRI) of the brain and cervical spine (Fig 2) was performed for suspected subtle intracranial pathology and a spinal origin of SAH (observed rarely). A lobulated 8-mm intradural, extramedullary lesion with internal hypointense signal was seen at the $\mathrm{T} 1 / 2$ level abutting the lateral surface of the spinal cord. Trace contrast enhancement was noted within the lesion. Adjacent hyperintense signal and susceptibility artefacts within the dural sac were also observed, suggestive of sentinel clot formation. The spinal cord was displaced slightly by the lesion with associated mild cord oedema. Radiological differential diagnosis at this juncture included cavernoma, largely thrombosed spinal aneurysm, other exophytic haemorrhagic 


\section{孤立性脊髓動脈瘤：蛛網膜下腔出血的一個罕見 原因}

\author{
宋咸東、梁錦榮、賴銘曦、邱麗珊
}

孤立性脊髓動脈瘤可能是突發性蛛網膜下腔出血的原因, 屬於罕見的 病變。本文報告一名 74 歲男子有突發性胸痛, 並延伸至頸部和背部, 隨後出現頭痛和神志不清。初步的電腦斷層掃描主動脈造影偶然發現 輕微的急性脊髓蛛網膜下腔出血。一組腦部的電腦斷層掃描進一步顯 示其急性㲊內蛛網膜下腔出血集中在腦後部, 並且腦室內有少量出 血, 但未見有顱內血管病變。隨後的磁共振成像顯示血栓脊髓硬膜內 動脈瘤周圍的血塊, 後以動脈瘤孤立術及手術移除。雖然這種情況很 罕見, 但因其破壞力高, 醫生須保持臨床的高度警覺性。本文並會討 論相關的病理學特點和臨床管理。

intramedullary tumour or slow-flow arteriovenous malformation (AVM).

Subsequent laminectomy and surgical exploration were performed for definitive diagnosis, which revealed a $7-\mathrm{mm}$ saccular aneurysm surrounded by fibrin and an old haematoma from $\mathrm{C} 7$ to T2 level. The aneurysm arose from and was incorporated with the radicular artery at $\mathrm{T} 1$ level, showing internal partial thrombosis. The aneurysmal sac was trapped and carefully excised without jeopardising the rest of the arterial supply to the cord. The patient had good clinical recovery in postoperative rehabilitation with no further neurological complaints.

\section{Discussion}

Compared with more common causes of spinal SAH like AVM, dural arteriovenous fistula (dAVF) and haemorrhagic spinal cord tumours, spinal artery aneurysm remains a rare entity with a reported incidence of less than 1 in 3000 spinal angiograms, according to a large-scale review by Pia and Djindjian. ${ }^{4}$ Ever since the first case report on spinal aneurysm back in 1930, ${ }^{5}$ experience from various studies remains limited mainly to isolated case reports and case series with small sample sizes.

Spinal aneurysms are distinct from intracranial counterparts in several ways. First, they occur mostly along the course of their parent arteries which have a small calibre and are less affected by atherosclerosis. ${ }^{6}$ On the contrary, intracranial aneurysms are well known for their predilection for branching points of large-sized arteries which are more haemodynamically challenged. Second, spinal aneurysms tend to be small in size, whereas giant aneurysms are exclusively found intracranially, especially in patients with connective tissue disease. Third, many spinal aneurysms are found to be dissecting aneurysms in histology, which explains their fusiform shape and lack of a surgical neck. ${ }^{5}$ This hinders direct surgical clipping during treatment planning.

For aetiology, isolated spinal aneurysms, as in our case, are rare lesions. More commonly, they are associated with concomitant vascular lesions or occlusions which recruit the spinal artery as a collateral route for supplying and increasing local blood flow. This, in turn, imposes haemodynamic stress and induces aneurysm formation along the parent arteries. Reported associations include spinal cord AVM, ${ }^{7}$ dAVF, ${ }^{8}$ aortic coarctation, ${ }^{5}$ Moyamoya disease, ${ }^{9}$ and bilateral vertebral artery occlusion. ${ }^{10}$ Another group of spinal aneurysms is related to underlying vasculopathies. Common examples include collagen vascular disease such as rheumatoid arthritis, ${ }^{11}$ mycosis, ${ }^{12}$ and syphilis. ${ }^{5}$

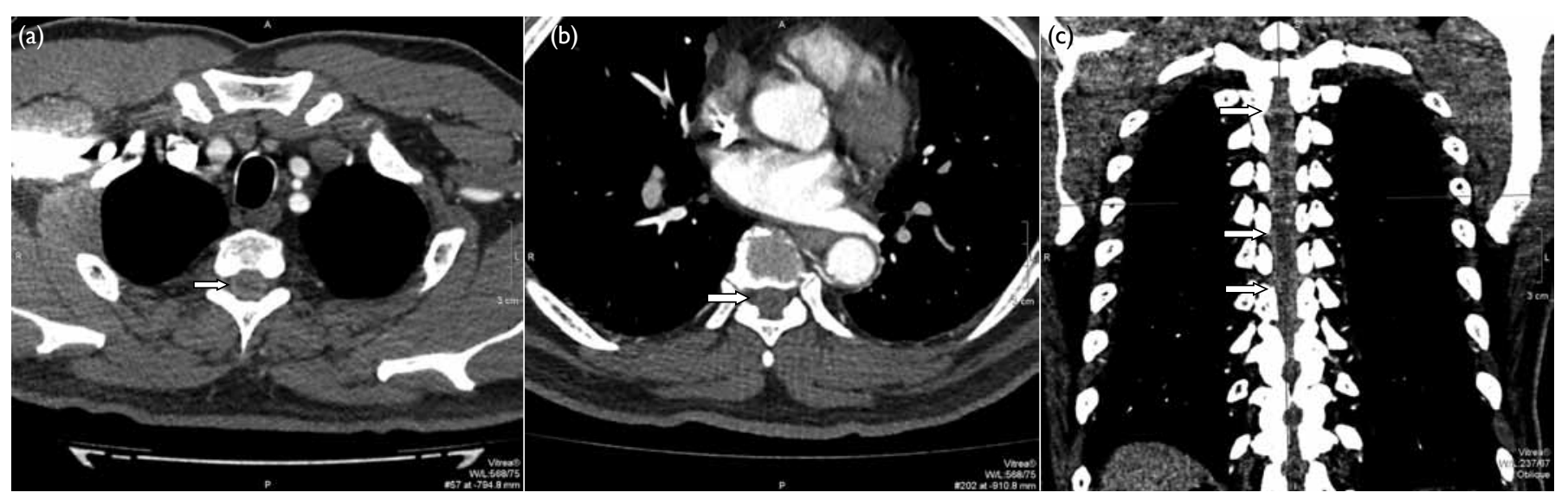

FIG I. (a, b) Axial and (c) coronal reformatted images of the contrast computed tomography (CT) aortograms demonstrate subtle hyperdensities within the dural sac at upper thoracic levels, suggesting acute spinal subarachnoid haemorrhage (arrows). The cerebrospinal fluid in normal subjects should be hypodense, similar to water attenuation on CT. The spinal cord is outlined as a central elongated hypodense structure simulating a contrast myelogram 


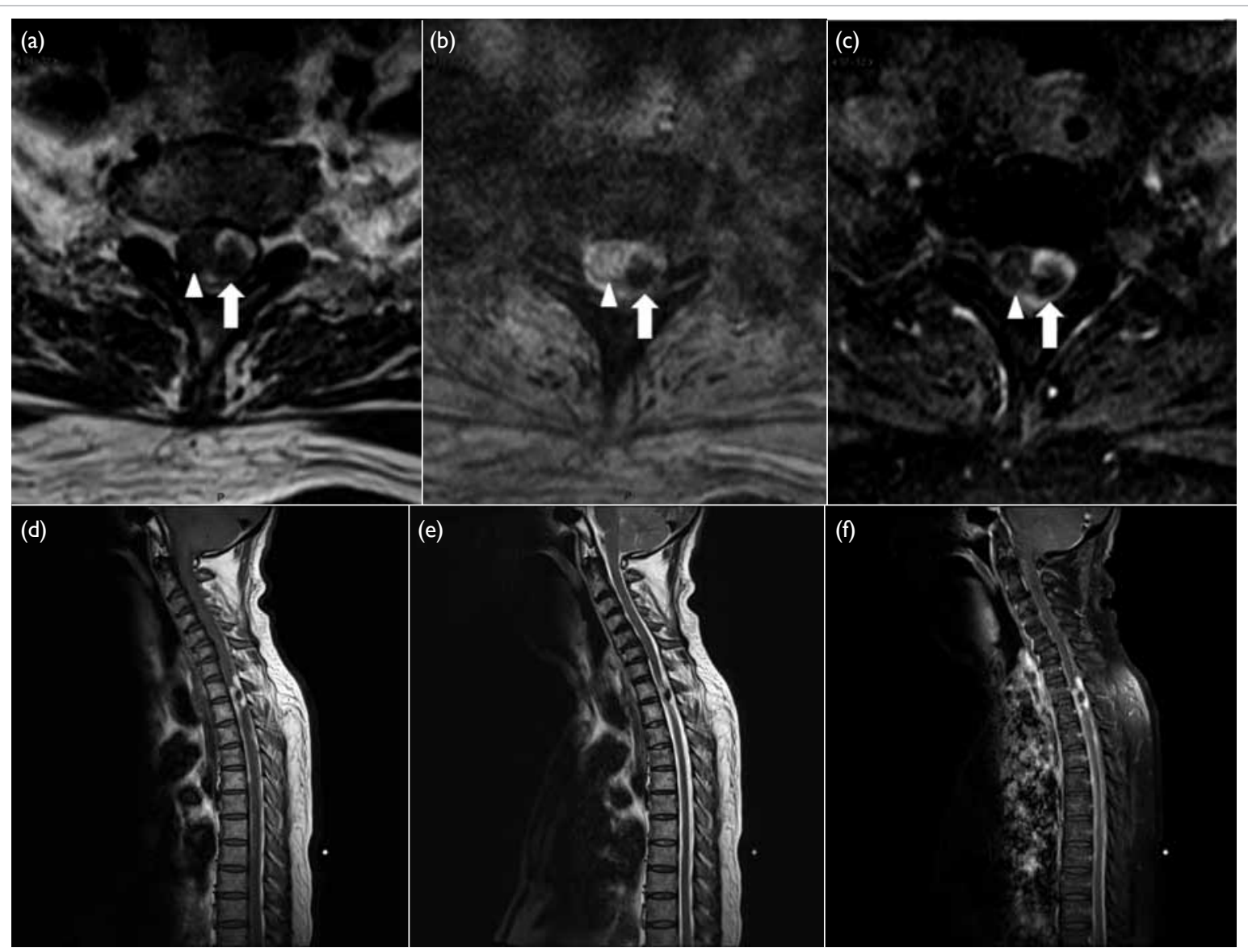

FIG 2. (a) Axial TI-, (b) T2- and (c) post-contrast fat-suppressed TI-weighted magnetic resonance imaging (MRI) of the spine at TI level shows a lobulated intradural, extramedullary hypointense lesion with subtle contrast enhancement (arrows) and surrounding hyperintense blood clot. The spinal cord (arrowheads) is displaced laterally with intramedullary T2-hyperintense oedema. Corresponding sagittal (d) TI-, (e) T2-, and (f) post-contrast fat-suppressed TI-weighted MRI of the spine also shows the lobulated intradural lesion and surrounding blood clot

The diagnosis of spinal artery aneurysm could be challenging and delayed due to its rarity. Most patients present with headache and backache related to aneurysmal rupture and SAH. Neurological deficits including paraparesis, quadriplegia, and cord compression have also been reported. ${ }^{13}$ As for investigations, MRI and DSA of the spine are sufficient to demonstrate the location and vascular anatomy of a spinal artery aneurysm on most occasions which, in turn, are valuable for treatment planning by neurosurgeons. The position of the aneurysm with respect to the spinal cord determines whether the anterior approach for transthoracic vertebrectomy or posterior laminectomy is most appropriate. In a large-scale literature review by Geibprasert et al, ${ }^{14} 32$ spinal artery aneurysms were studied, in which the majority $(62.5 \%)$ arose from the anterior spinal artery. Origin from the radicular artery, as in our case, was scarcely seen $(n=2)$. The authors also observed that posterior spinal artery aneurysms were predominantly isolated dissecting aneurysms. On the contrary, those from the anterior spinal artery are more diverse in aetiology, eg, related to candidiasis and connective tissue disease, which implies a non-surgical management approach with medical treatment for the underlying disorder. Even for isolated dissecting aneurysms from the anterior axis, surgical ligation or endovascular embolisation is still limited by increased risk of postoperative complications including spinal cord infarction due to possible compromise of the dominant arterial supply to the cord. Options of surgical approach include resection and wrapping of the aneurysmal sac, with possible microvascular reconstruction in individual cases. Rare cases of spontaneous complete healing of the dissecting aneurysm have been reported, ${ }^{12}$ but prompt treatment should not be delayed due to the associated severe complications. 


\section{Conclusion}

Spinal artery aneurysms are rare culprits of SAH, with different morphological features of their intracranial counterparts. Associations with concurrent vascular lesions and vasculopathy are frequent, with a minority of cases being isolated in aetiology. Magnetic resonance imaging and DSA of the spine show their merit in delineating the location and vascular anatomy of a spinal artery aneurysm, which are key determinants in management planning. Surgical treatment should be prompt and performed cautiously in view of possible substantial neurological deficit when the arterial supply of the cord is jeopardised.

\section{References}

1. Feigin VL, Lawes CM, Bennett DA, Barker-Collo SL, Parag $\mathrm{V}$. Worldwide stroke incidence and early case fatality reported in 56 population-based studies: a systematic review. Lancet Neurol 2009;8:355-69.

2. Nieuwkamp DJ, Setz LE, Algra A, Linn FH, de Rooij NK, Rinkel GJ. Changes in case fatality of aneurysmal subarachnoid haemorrhage over time, according to age, sex, and region: a meta-analysis. Lancet Neurol 2009;8:63542.

3. van Gijn J, Kerr RS, Rinkel GJ. Subarachnoid haemorrhage. Lancet 2007;369:306-18.

4. Pia HW, Djindjian R. Spinal angiomas: advances in diagnosis and therapy. Berlin: Springer Verlag; 1987.

5. Rengachary SS, Duke DA, Tsai FY, Kragel PJ. Spinal arterial aneurysm: case report. Neurosurgery 1993;33:125-9; discussion 129-30.

6. Leech PJ, Stokes BA, ApSimon T, Harper C. Unruptured aneurysm of the anterior spinal artery presenting as paraparesis. Case report. J Neurosurg 1976;45:331-3.

7. Konan AV, Raymond J, Roy D. Transarterial embolization of aneurysms associated with spinal cord arteriovenous malformations. Report of four cases. J Neurosurg 1999;90(1 Suppl):148-54.

8. Malek AM, Halbach VV, Phatouros CC, et al. Spinal dural arteriovenous fistula with an associated feeding artery aneurysm: case report. Neurosurgery 1999;44:877-80.

9. Walz DM, Woldenberg RF, Setton A. Pseudoaneurysm of the anterior spinal artery in a patient with Moyamoya: an unusual cause of subarachnoid hemorrhage. AJNR Am J Neuroradiol 2006;27:1576-8.

10. Kawamura S, Yoshida T, Nonoyama Y, Yamada M, Suzuki A, Yasui N. Ruptured anterior spinal artery aneurysm: a case report. Surg Neurol 1999;51:608-12.

11. Toyota S, Wakayama A, Fujimoto Y, Sugiura S, Yoshimine T. Dissecting aneurysm of the radiculomedullary artery originating from extracranial vertebral artery dissection in a patient with rheumatoid cervical spine disease: an unusual cause of subarachnoid hemorrhage. Case report. J Neurosurg Spine 2007;7:660-3.

12. Berlis A, Scheufler KM, Schmahl C, Rauer S, Götz F, Schumacher M. Solitary spinal artery aneurysms as a rare source of spinal subarachnoid hemorrhage: potential etiology and treatment strategy. ANJR Am J Neuroradiol 2005;26:405-10.

13. Yahiro T, Hirakawa K, Iwaasa M, Tsugu H, Fukushima $\mathrm{T}$, Utsunomiya $H$. Pseudoaneurysm of the thoracic radiculomedullary artery with subarachnoid hemorrhage. Case report. J Neurosurg 2004;100(3 Suppl Spine):312-5.

14. Geibprasert S, Krings T, Apitzsch J, Reinges MH, Nolte KW, Hans FJ. Subarachnoid hemorrhage following posterior spinal artery aneurysm. A case report and review of the literature. Interv Neuroradiol 2010;16:183-90. 